\title{
Synthesis and characterization of nickel sulphoselenide thin films
}

\begin{abstract}
NiSSe thin film has been synthesized onto indium tin oxide (ITO) glass substrates using an electro deposition technique and the structural and optical properties of the films are studied. The resulted thin films are characterized using X-ray diffraction analysis and scanning electron microscopy to determine the crystallographic and morphological properties. Results proved that nickel sulphoselenide thin films are polycrystalline in nature with a good uniformity. Optical analyses proved the direct band gap of the films. Well-adherent and dark-colored thin films are derived from the cathode electro deposition. Experimental results proved that NiSSe thin films are capable to be used in photo electrochemical cell applications.
\end{abstract}

Keywords: thin film, electro deposition, nickel sulphoselenide
Volume 2 Issue I - 2018

\author{
Joseph Sahaya Anand T \\ Faculty of Manufacturing Engineering, Universiti Teknikal \\ Malaysia Melaka (UTeM), Malaysia
}

\begin{abstract}
Correspondence: Joseph Sahaya Anand T, Faculty of Manufacturing Engineering, Universiti Teknikal Malaysia Melaka (UTeM), 76100 Hang Tuah Jaya, Durian Tunggal, Melaka, Malaysia; Email anand@utem.edu.my
\end{abstract}

Received: August 09, 2017| Published: January 24, 2018

\section{Introduction}

Usable electric current can be synthesized from photo electrochemical cells. The unit cells are group together to form a series of solar panel. The arrays of solar panel are generally placed under glass, polymer or plastic as a protection from the weather. ${ }^{1}$ The usage of transition metal chalcogenide thin film in solar energy conversion can lead to a good path in developing a bright future for photovoltaic application. Transition metal chalcogenide are materials of semiconductors, which are capable to be used as an efficient photovoltaic material. ${ }^{2-4}$ From the previous research, transition metal chalcogenides $\mathrm{NiX}_{2}(\mathrm{X}=\mathrm{Se}, \mathrm{S}$ and $\mathrm{Te})$ and $\mathrm{MoX}_{2}(\mathrm{X}=\mathrm{Se}$, $\mathrm{S}$ and $\mathrm{Te}$ ) have been showing a good result in terms of optical and semiconducting properties as a new thin film material for solar energy in effort to replace the conventional method. ${ }^{5-9}$ Transition metal chalcogenide thin films preparation by electrochemical methods is attracting a special attention as it is relatively affordable, simple and convenient for large area deposition. ${ }^{5}$

\section{Methodology}

ITO conductive glass substrates are ultrasonically cleaned in ethanol and subsequently in distilled water for 10 minutes each at $60^{\circ} \mathrm{C}$ then dried. The electrolyte used to deposit the NiSSe thin film is derived from aqueous solution of $0.05 \mathrm{M}$ nickel (II) sulfate hexahydrate $\left(\mathrm{NiSO}_{4} \cdot 6 \mathrm{H}_{2} \mathrm{O}\right), 0.05 \mathrm{M}$ selenium dioxide $\left(\mathrm{SeO}_{2}\right)$ and $0.05 \mathrm{M}$ sodium thiosulfate pentahydrate $\left(\mathrm{Na}_{2} \mathrm{~S}_{2} \mathrm{O}_{3} .5 \mathrm{H}_{2} \mathrm{O}\right)$ diluted in $100 \mathrm{ml}$ distilled water. Each reactive supply the required $\mathrm{Ni}^{2+}, \mathrm{Se}^{2-}$ and $\mathrm{S}^{-}$respectively. $0.03 \mathrm{M}$ of additive triethanolamine (TEA) is added into the solution for improving the longevity of the deposition electrolyte as well as the adhesion of the deposited films.

\section{Cyclic voltammetry (CV), electrochemical deposition and characterization techniques}

The range of potential limit between -2.00 to $2.00 \mathrm{~V}$ for cyclic voltammetry $(\mathrm{CV})$ is selected to determine the suitable potential rate for the electro deposition to take place by using Princeton Applied Research Model Versa STAT 3 Potentiostat. Each thin film thickness was estimated using a gravimetric weight difference method. X-ray diffractograms of the thin film is obtained from a PAN analytical
XPERT PROMPD PW 3040/60 diffractometer using monochromatic CuK radiation $(\lambda=1.5148 \AA)$. The morphological analysis of NiSSe thin films was studied by using TM3030 Plus Tabletop Scanning Electron Microscope (SEM) while the compositional study was conducted using Swift EDTM3030 Plus Energy Dispersive X-ray Spectroscopy (EDX). Optical absorption is studied using a Shimadzu 1700 UV-Vis Spectrophotometer in the wavelength region of 200$1100 \mathrm{~nm}$

\section{Results and discussion}

Figure 1 shows the cyclic voltammetry of NiSSe where the forward scan begins to rise at higher potential, $-1.0 \mathrm{~V}$. During the reverse scan, co-deposition occurs in the negative potential range, however the current value is reduced as the deposition potential is scanned towards more negative value (anodic region). Deposition potentials of $-0.9 \mathrm{~V}$ is chosen to deposit the NiSSe thin film. The structural characterization and analysis using XRD (Figure 2) are performed by setting the incidence angle as $1.5^{\circ}$ in order to reduce the intensity of the radiation reflected by the substrate. It is observed that initially at lower deposition time ITO substrate peaks are dominant whereby when the thickness/time of films increases the intensity of film peaks are more visible. On the other hand when the deposition time reaches 30 minutes the film peaks suppresses mainly due to the peel off condition. The above results confirmed the presence of NiSSe thin films and their stoichiometry crystalline structure.

High-intensity peaks of diffractogram in figure of the films reveal the completeness of crystallization process. This is due to the fact that the crystallinity increases with the increase of deposition time. ${ }^{8}$ Enhancement of grain crystallinity with thickness, as presented in thickness measurement is due to increase in deposition time and growth mechanism involved in the film formation. The enhancement of microcrystalline growth that is initiated along the substrate planes have resulted in some preferred orientation crystals to evolve only at longer deposition times. The preferred orientation is attributed to the enhancement in surface diffusion of the absorbed species with the increase of thickness resulting in an improvement in crystallinity of NiSSe thin films. In all films, the enhancement of the planes and the improved crystallinity with film thickness is remarkable irrespective of the electrolyte bath composition. 


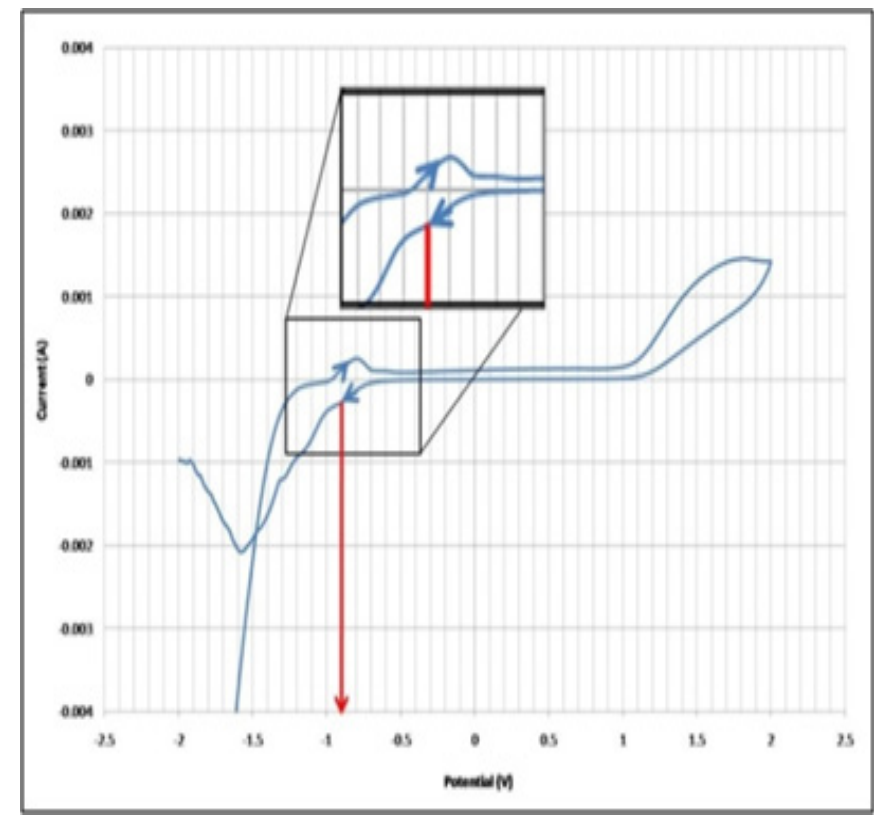

Figure I Cyclic voltammogram of NiSSe electrolyte.

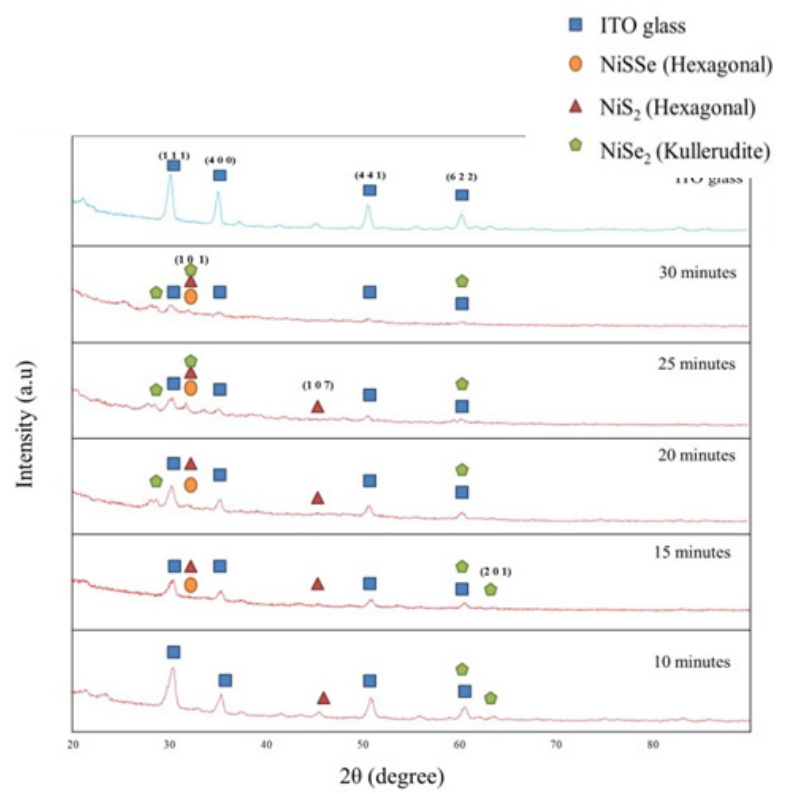

Figure $2 \mathrm{X}$-ray diffraction pattern of NiSSe thin films deposited at various deposition times.

The surface morphology of NiSSe thin films are shown in Figure 3 deposited with 30minutes deposition time. It is recognized that the unsymmetrical crystallites forms on ternary chalcogenide films as observed in NiSSe thin film due to the separation of chalcogenides phases (selenium and sulphide). ${ }^{9}$ The separation of chalcogenide phases is observable in ternary chalcogenide films as reported. ${ }^{8}$ The morphology of the surface is better in films with selenium content. This is due to better orientation of crystal in the films upon addition of selenium. ${ }^{6}$ At longer deposition times, the structure of the films starts to break into grains (flakes) although still adhering to the substrate. The grains of the materials keeps on growing with time, causing the films to break and forming flake-like structures upon reaching the maximum grain stress point. The cracking in thin films is attributed to drying shrinkage in this case of hydrous films.

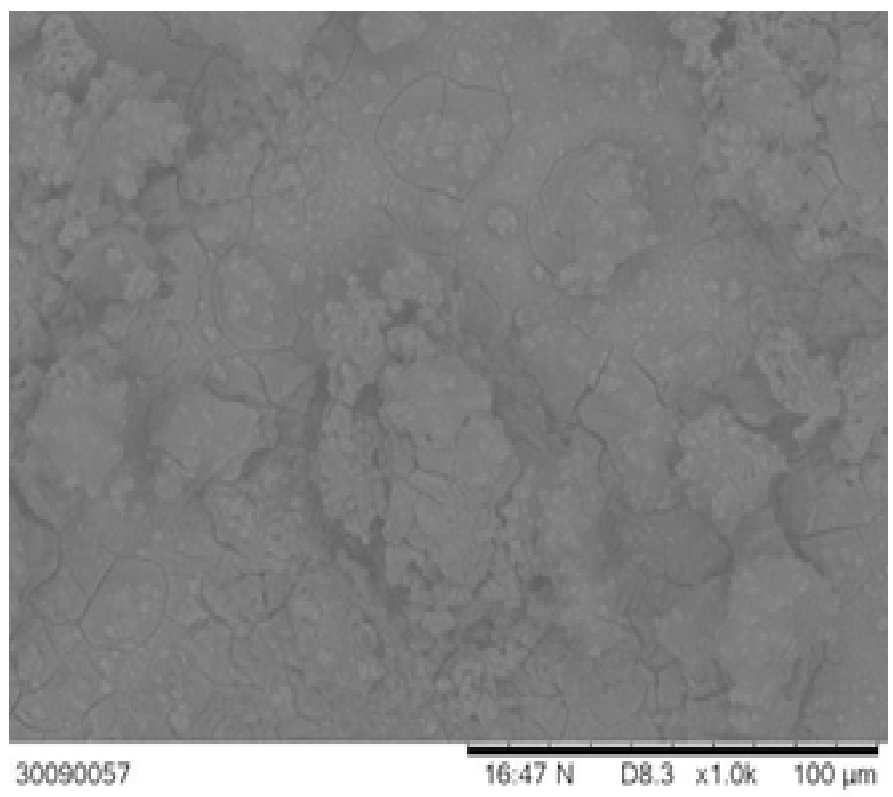

SE

Figure 3 SEM planar images of NiSSe thin film deposited at 30 minutes deposition time under 1000x magnification.

Optical studies revealed the absorption spectra of the as deposited NiSSe thin films. They focused their analysis in the wavelength range 200-1100 $\mathrm{nm}$ without considering losses due to reflection and transmission at room temperature atmosphere. Light intensity analysis of an optical spectrum of a material is imperative for solar cell application. This employed to determine key optical properties such as extinction coefficient (k), absorption coefficient ( $\alpha$ ), optical band gap (Eg) etc. The absorbance spectrum of these optical studies is considered as this value calculated for the synthesized samples to its light absorption nature. From this spectrum and its corresponding wavelength, the type of band transition and its energy gap were derived from the following mathematical relation (1). ${ }^{8}$

$$
\alpha \mathrm{h} v=\mathrm{A}\left(\mathrm{h} v-\mathrm{E}_{\mathrm{g}}\right)^{\mathrm{n}}
$$

Equation (1)

where $\mathrm{A}$ is an energy dependent constant, $\mathrm{Eg}$ is the band gap energy $(\mathrm{eV})$ and $\alpha$ is the photon energy and $\mathrm{h}$ is the plank constant ( $\left.6.627 \times 10^{-34}\right), v$ is light frequency, substituting the values of $\mathrm{n}$ as $1 / 2$ (direct) and 2(indirect).

The synthesized NiSSe thin films at different deposition times with their $(\alpha h v)^{2}$ vs. $h v$ plots are shown in Figure 4A whereas Figure $4 \mathrm{~B}$ shows the range of these band gap values for NiSSe films lying between $1.30-1.15 \mathrm{eV}$. The obtained band gap range is very much similar to the reported. ${ }^{9}$ It is observed that the energy bandgap is directly proportional to the deposition time. The change in the band gap values corresponding to thickness increase with fixed deposition condition such as temperature, solution concentration etc. It is found that the band gaps of NiSSe films are intermediate between those $\mathrm{NiSe}_{2}$ and $\mathrm{NiS}_{2}$. This can be understood due to the stoichiometry of the films. It can be concluded that the optical band gap energy of all types of films decreases as the deposition time of the film increases. This result correlates to film thickness, whereby an increase in deposition time of the films result in greater thickness. 


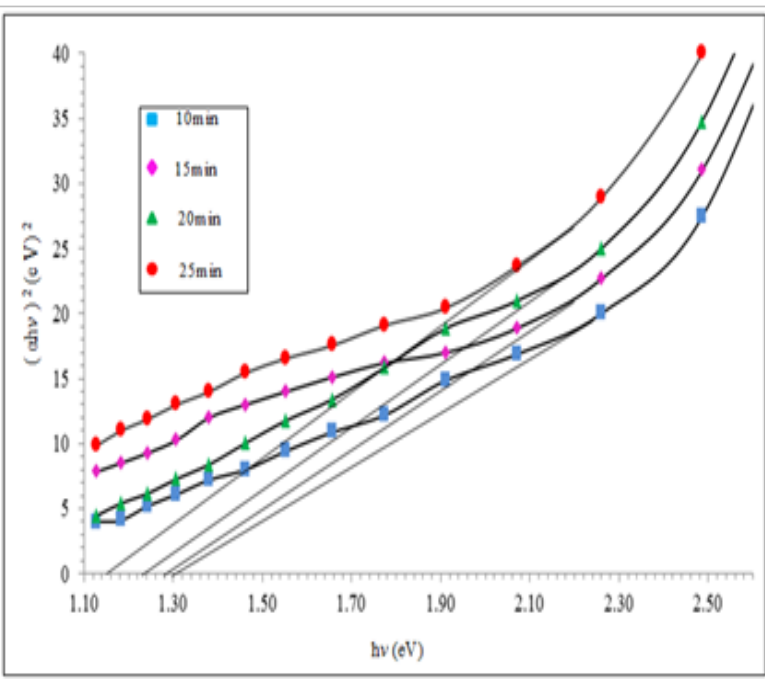

A)

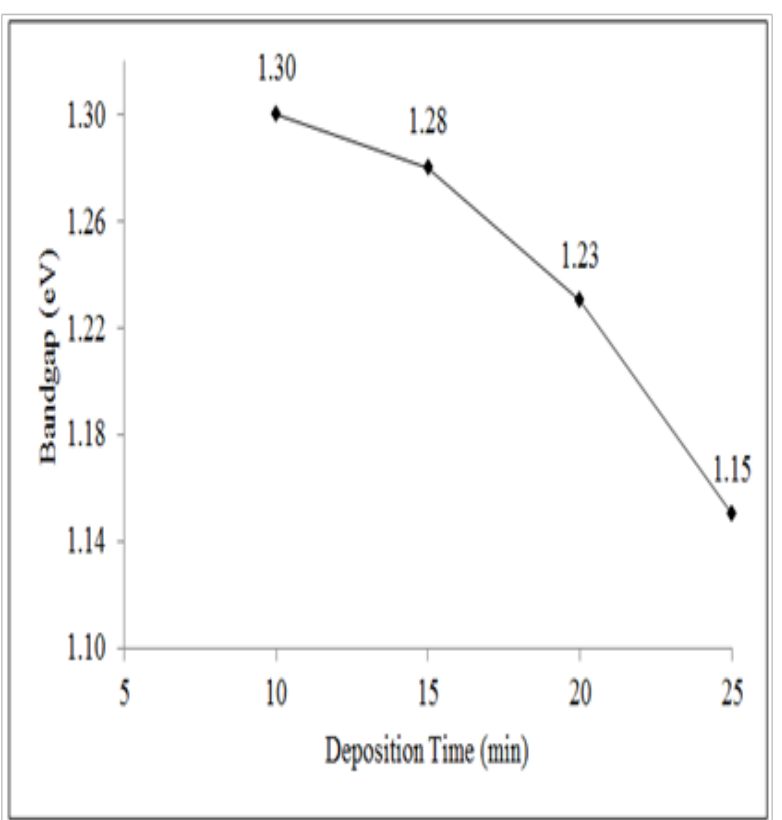

B)

Figure 4 Optical absorbance variance of NiSSe thin film deposited at different deposition times $(A)(\alpha h v)^{2}$ vs. hv and $(B)$ band gap vs. deposition time.

\section{Conclusion}

To be concluded, NiSSe thin films are successfully deposited on ITO-coated glass. All films obtained are well adhered to the substrates undergoing 'ion-by-ion' growth mechanism. This mechanism is common in the transitional metal chalcogenide thin film preparation whereby initial induction time makes the ions to form as a group. XRD analysis of the films proved that NiSSe thin films are polycrystalline in nature. The morphological characteristics show that the NiSSe are well distributed onto the ITO glass substrates. Optical studies show the direct optical band gap energy of the film. Semiconductor parameters of the film revealed that the NiSSe thin films are p-type material showing that thin films are capable as photo electrochemical cell material.

\section{Acknowledgements}

The work presented in this manuscript was supported by the Faculty of Manufacturing Engineering, Technical University of Malaysia Melaka (UTeM).

\section{Conflict of interest}

Author declares that there is no conflict of interest.

\section{References}

1. Dhanasekaran V, Mahalingam T, Rhee JK, et al. Structural and optical properties of electrosynthesized ZnSe thin films. Optik. 124(3): 255260.

2. Yadav AA, Masumdar EU. Photoelectrochemical performances of n-CdS ${ }_{1-\mathrm{x}} \mathrm{Se}_{\mathrm{x}}$ thin films prepared by spray pyrolysis technique. Sol Ener. 2010;84(8):1445-1452.

3. Gujarathi DN, Solanki GK, Deshpande MP, et al. PEC behaviour of mixed single crystals of tungsten sulphoselenide grown by a CVT technique. Solar Energy Materials and Solar Cells. 2006;90(16):2630-2639.

4. Kokate AV, Asabe MR, Delekar SD, et al. Photo electrochemical properties of electrochemically deposited CdIn $\mathrm{S}_{4}$ thin films. Journal of Physics and Chemistry of Solids. 2006;67(11):2331-2336.

5. Pathan HM, Lokhande CD. Deposition of metal chalcogenide thin films by successive ionic layer adsorption and reaction (SILAR) method. Bull Mater Sci 2004;27(2):85-111

6. Anand TJS, Zaidan MAA, Shariza S. Effect of additives on optical measurements of $\mathrm{NiSe}_{2}$ thin films. Procedia Engineering. 2013;53:555-561.

7. Anand TJS, Rajes KM, Zaidan AAM. Electrosynthesized $\mathrm{NiS}_{2}$ thin film and their optical and semiconductor studies. Reports in Electrochemistry. 2013;3:25-29.

8. Shariza S, Anand TJS. Effect of Deposition Time on Structural and Optical Properties of Molybdenum Chalcogenides Thin Films. Chalcogenide Letters. 2011;8(9):529-539.

9. Anand TJS, Shariza S. A study on molybdenum sulphoselenide $\left(\mathrm{MoS}_{\mathrm{x}} \mathrm{Se}_{2-\mathrm{x}}, 0<\mathrm{x}<2\right)$ thin films: growth from solution and its properties. Electrochimica Acta. 2012;81:64-73. 